\title{
CMOS Compatible Midinfrared Wavelength-Selective Thermopile for High Temperature Applications
}

\author{
Huchuan Zhou, Piotr Kropelnicki, and Chengkuo Lee, Member, IEEE
}

\begin{abstract}
In this paper, the design, fabrication, and testing of a CMOS compatible mid-infrared (mid-IR) thermopile sensor comprising a stacked double layer thermopile and an interferometric absorber is reported. The devices are all fabricated in CMOS compatible process. The length and width of the thermocouple are 600 and $12 \mu \mathrm{m}$, respectively. One thermopile consists of 96 thermocouple pairs. The thickness of the poly-Si strips is $300 \mathrm{~nm}$ and the thickness of the $\mathrm{SiO}_{2}$ electrical isolation layer is $150 \mathrm{~nm}$. The interferometric absorber is formed by a stacked three layer of 7-nm TiN, 250-nm amorphous silicon, and 300-nm Al. The measurement using blackbody with temperature of $470{ }^{\circ} \mathrm{C}$ was conducted at ambient temperature from $-50{ }^{\circ} \mathrm{C}$ to $300{ }^{\circ} \mathrm{C}$. The results show that the responsivity and the detectivity of this thermopile mid-IR sensor vary from 130 to $463 \mathrm{~V} / \mathrm{W}$ and $3.8 * 10^{6} \mathrm{~cm} * \mathrm{~Hz}^{1 / 2} * \mathrm{~W}^{-1}$ to $1.3 * 10^{7} \mathrm{~cm} * \mathrm{~Hz}^{1 / 2} * \mathrm{~W}^{-1}$, respectively. And the time constant of the mid-IR sensor is $33 \mathrm{~ms}$. The maximum output voltage is measured at $190{ }^{\circ} \mathrm{C}$, where the responsivity and the detectivity are $425.7 \mathrm{~V} / \mathrm{W}$ and $1.25 *$ $10^{7} \mathrm{~cm} * \mathrm{~Hz}^{1 / 2} * \mathrm{~W}^{-1}$, respectively.

[2014-0033]
\end{abstract}

Index Terms-Thermopile, infrared (IR) sensor, responsivity, detectivity, interferometric absorber.

\section{INTRODUCTION}

$\mathbf{I}$ $\mathrm{N}$ RECENT years, infrared (IR) sensors fabricated with complementary metal-oxide semiconductor (CMOS) compatible process are widely used for various applications [1]-[3]. CMOS compatible IR sensors have relatively small footprint, lower weight and faster response speed. Besides, these IR sensors can be monolithically integrated with readout integrated circuits (ICs) for further signal amplification or other processing [4], [5]. In addition to the traditional

Manuscript received January 29, 2014; revised March 18, 2014; accepted March 20, 2014. Date of publication June 2, 2014; date of current version January 30, 2015. This work was supported in part by the Science and Engineering Research Council under Grant 1021650084 and Grant 1220103064 through the Agency for Science, Technology, and Research, Singapore; and in part by the National Research Foundation Competitive Research Programme, Singapore, under Grant R-263-000-A27-281. Subject Editor C.-J. Kim.

H. Zhou is with the Department of Electrical and Computer Engineering, National University of Singapore, Singapore 117576; and is also with the Institute of Microelectronics, Agency for Science, Technology, and Research, Singapore 117685 (e-mail: a0077704@ nus.edu.sg).

P. Kropelnicki is with the Institute of Microelectronics, Agency for Science, Technology, and Research, Singapore 117685 (e-mail: kropelnicki@gmail.com).

C. Lee is with the Department of Electrical and Computer Engineering, National University of Singapore, Singapore 117576 (e-mail: elelc@nus.edu.sg).

Color versions of one or more of the figures in this paper are available online at http://ieeexplore.ieee.org.

Digital Object Identifier 10.1109/JMEMS.2014.2322675 application area of IR sensors, e.g. imaging, target surveillance and temperature monitoring, substance detectors grow in interest using wavelength selective sensing to analyze specific molecular bonds [6], [7].

Among these IR sensors, thermopile based IR sensors have great advantages due to the characteristics of no active operation power [8]-[10]. A thermopile is a group of serialconnected thermoelectric strip pair which is formed by two materials with different Seebeck coefficients. Due to the Seebeck effect, thermoelectric voltage is generated linearly corresponding to the temperature difference between the hot-junction and the cold-junction of thermopile structure [11]-[15], which means the thermopile IR sensor is a passive sensor generating voltage signal as a function of the temperature difference. Most of the IR sensors, like quantum sensors and bolometers [16], can not work properly at high temperatures [17]. However, a lot of applications for IR based chemical sensors, e.g. oil gas detection, require working at high temperature, thus a harsh environment of $200{ }^{\circ} \mathrm{C}$ to $300{ }^{\circ} \mathrm{C}$. Therefore, we are keen at exploring the high temperature characteristics of thermopile based IR sensors for potential applicationsat harsh environment.

Various thermoelectric materials, including semiconductors and alloys, have been investigated so far [18]-[23]. Among these materials, $\mathrm{Bi}_{2} \mathrm{Te}_{3}$ and $\mathrm{Sb}_{2} \mathrm{Te}_{3}$ generate the highest figureof-merit, i.e., ZT, within $200^{\circ} \mathrm{C}$, because of their relative good Seebeck coefficient and low electrical resistance. However, these materials are not CMOS compatible and therefore it is impossible to integrate them into standard CMOS manufacturing lines [24]. Alternative materials, like nickel and chromium, are widely used, however their low Seebeck coefficient limits them from achieving high performance [25], [26]. Recently, CMOS compatible polycrystalline silicon (poly-Si) based IR sensors have been extensively studied [27]-[31]. However, the reported data only reveal the thermoelectric properties at room temperature.

The selection of supporting materials of the thermopile IR sensor is very critical in addition to the selection of thermoelectric materials. High thermal resistance, high mechanical and thermal stability are desirable for supporting materials. Polymers, e.g. SU-8, are emerging as attractive materials for this purpose [32]-[34], due to their relative low thermal conductance, flexibility [35] and potential on integration as biocompatible layer for bio-chips [36]. However, polymer is not mechanically reliable with respect to fabrication 
process temperature of main-stream thermoelectric materials, i.e., poly-Si at $1000{ }^{\circ} \mathrm{C}$. Therefore, the $\mathrm{SiO}_{2}$, a widely used CMOS compatible dielectric material, is utilized as supporting materials with additional advantages of its low thermal conductance, high thermal and mechanical stability [36].

Besides, the wavelength selective filter is very crucial in the realization of IR based chemical sensors, since the output signal is a function of the amount of specific molecules, and the signature of the particular moleculeis recognized in terms of the wavelength [38]. In 1991, Liddiard did an analytical study on interferometric structures based absorber which comprises three stacked layers [39]. By varying the thickness of the three layers, the absorption spectrum of the interferometric absorber can be aligned to the desired wavelength. In contrast to the common approach of packaging the wavelength selective filter and IR radiation sensor in a metalcan to form an IR based chemical sensor, Liddiard's approach shows another way of making IR radiation sensor becomes wavelength selective. Hence, authors use the interferometric based wavelength-selective absorber in the proposed thermopile based IR sensor in this paper. To explore the feasibility of using thermopile based IR sensor aiming at oil gas sensing applications, i.e., a harsh environment [40], authors explore temperature-dependent characteristics for heavily doped poly$\mathrm{Si}$ thermopile structure using CMOS materials and process.

\section{DESIGN CONSIDERATION}

\section{A. Design of Thermopile}

A thermopile is a series of electrically connected pairs of thermocouples which comprises a pair of materials with different Seebeck coefficients. According to the Seebeck effect, thermoelectric power is generated when there is a temperature difference between the two ends of the thermopile. The end with higher temperature is known as hot-junction while the other one is called cold-junction. The output voltage $V_{\text {out_single }}$ between the hot-junction and cold-junction of a single thermocouple can be described mathematically as [41]:

$$
V_{\text {out_single }}=\Delta T\left(\alpha_{1}-\alpha_{2}\right)=\Delta T \alpha_{12},
$$

where $\Delta \mathrm{T}$ is the temperature difference between the hotjunction and cold-junction, and $\alpha_{1}$ and $\alpha_{2}$ are the Seebeck coefficients of the two materials, which form the thermocouple. The difference between $\alpha_{1}$ and $\alpha_{2}$ is defined as $\alpha_{12}$.

In a design of infrared sensor using thermopile structure the hot-junction is usually close to an infrared absorber which absorbs the power from infrared radiation and converts it into heat. That causes a temperature rise at the hot-junction. The cold-junction, on the other hand, is usually connected to a heat sink, e.g. a single crystal silicon substrate, which presents the ambient temperature. In order to get a significant temperature difference between the cold-junction and hot-junction, these two junctions should be isolated. One of the most widely used structures to fulfill the isolation is a suspended structure, which is utilized in this paper.

The thermopile is an array of thermocouples so the output voltage of the thermopile $V_{\text {out }}$ should be the sum of $V_{\text {out }}$ single of each thermocouple. $V_{\text {out }}$ of a thermopile with $N$ thermocouples can be described as:

$$
V_{\text {out }}=N V_{\text {out_single }}=N \Delta T \alpha_{12},
$$

1) Working Principle and Theoretical Analysis of Thermopile: There are two significant parameters to evaluate the performance of thermopile: the responsivity, $R_{v}$, and the specific detectivity, $D * . R_{v}$ stands for the output of the thermopile which corresponds to the output efficiency of the sensor while $D *$ stands for how precise the sensor can detect.

$R_{v}$ is defined as:

$$
R_{v}=\frac{V_{\text {out }}}{P_{\text {absorb }}}
$$

where $P_{\text {absorb }}$ is the infrared power that is absorbed by the thermopile and can be calculated by:

$$
P_{\text {absorb }}=\eta \varphi_{0} A,
$$

where $\eta$ is the absorption rate of the absorber, $\varphi_{0}$ is the infrared radiation power density and $A$ is the area of absorber. According to the Stefan-Boltzmann law, the radiance power density from the source to the thermopile, $\varphi_{0}$, with field view of $2 \theta$ can be expressed as:

$$
\varphi_{0}=\sigma\left(T_{s}^{4}-T_{0}^{4}\right) \sin ^{2} \theta
$$

where $\sigma$ is Stefan-Boltzmann constant, $T_{s}$ is the temperature of source, $T_{0}$ is the target temperature which, in this case, is the temperature of the sensor or the ambient temperature.

According to equation (2), (3) and (4), the expression of $R_{v}$ can be converted to:

$$
R_{v}=\frac{N \Delta T \alpha_{12}}{\eta \varphi_{0} A}
$$

According to reference [38], the temperature difference $\Delta T$ can be expressed as:

$$
\Delta T=P_{\text {absorb }} * R_{\text {ther }}=\eta \varphi_{0} A R_{\text {ther }},
$$

where $R_{t h e r}$ is the thermal resistance. By inserting equation (7) into equation (6) $R_{v}$ can be defined as:

$$
R_{v}=\frac{N P_{\text {absorb }} R_{\text {ther }} \alpha_{12}}{P_{\text {absorb }}}=N R_{\text {ther }} \alpha_{12} .
$$

The $R_{\text {ther }}$ is determined with the thermal conductivity of the materials and the dimensions of the thermopile structure. The detailed analysis is shown in our previous work [42].

Another significant parameter, $D *$ is defined as:

$$
D^{*}=\sqrt{A \Delta f} / N E P,
$$

where $\Delta f$ is the frequency bandwidth of the read out system, NEP is the noise equivalent power.

NEP represents the signal power that gives a signal-to-noise ratio of one in a one hertz output bandwidth. $D *$ is inverse to the NEP and is normalized by the absorption area and signal bandwidth. The NEP indicates the value of signal which can be detected by the sensor.

NEP can be expressed as:

$$
N E P=V_{n} / R_{v} .
$$


$V_{n}$ is the equivalent noise voltage. Since there is no current flow through the IR sensor using thermopile structure there is no $1 / f$ noise, therefore the main noise source is Johnson noise [32] and $V_{n}$ can be expressed as:

$$
V_{n}=\sqrt{4 k T R \Delta f}
$$

where $k$ is Boltzmann constant, $T$ is the temperature of thermopile (in kelvin) and $R$ is the electrical resistivity. Then the detectivity can be calculated as

$$
D^{*}=R_{v} \sqrt{A / 4 k T R} \text {. }
$$

2) Parameter Study of the Materials Used to Build the Thermopile: According to the equations mentioned in the previous section, the properties of the materials used as thermocouple are crucial to the performance of the thermopile based IR sensor. The efficiency of a thermoelectric material is determined by the dimensionless figure of merit, $Z T$ [43],

$$
Z T=\frac{\alpha^{2}}{\rho C} T,
$$

where $\alpha$ is the Seebeck coefficient, defined as the thermoelectric voltage produced per degree temperature difference, $\rho$ is the electrical resistivity, $C$ is the thermal conductivity, and $T$ is the temperature of the sensor [44], [45].

Among the reported thermoelectric materials used in thermopiles, $\mathrm{Bi}_{2} \mathrm{Te}_{3}$ and $\mathrm{Sb}_{2} \mathrm{Te}_{3}$ are the well-known n-type and p-type materials which generate the highest figure-of-merit, i.e., ZT, within $200{ }^{\circ} \mathrm{C}$. However, these materials are not CMOS compatible. For that reason these two materials cannot be integrated into standard CMOS manufacturing lines. Although some thin film metal materials, e.g. nickel and chromium, are also used in thermopiles, their low Seebeck coefficient limits them from achieving high performance. Recently semiconductor based thermopiles have been presented using Germanium (Ge), Silicon carbide $(\mathrm{SiC})$ and polycrystalline silicon (poly-Si) which can be fabricated using CMOS compatible process. J. Xie et al. have studied the thermoelectric properties of heavily doped poly-Si at room temperature [29].

In this paper a study on the thermoelectric properties of heavily doped poly-Si up to $300{ }^{\circ} \mathrm{C}$ is done to demonstrate the thermopile performance in different temperature.

In this paper heavily doped poly-Si was studied because of its good thermoelectric performance [43]. The implantation conditions of the poly-Si test structures used in the experiment are the same as we did in previous work [42]. The thickness of the poly- $\mathrm{Si}$ is $300 \mathrm{~nm}$.

In order to study the electric resistivity of the heavily doped poly-Si, we utilized van-der-Pauw structure as shown in Fig.1. Four-point method was utilized to get the average resistivity of the poly-Si. The contacts are numbered from 1 to 4 in a counter-clockwise order, beginning at the top-left contact, as shown in Fig.2.

The average resistivity of a sample is given by

$$
\rho=R_{S} * t,
$$

where $R_{S}$ is the sheet resistance and $t$ is the thickness of the poly- $\mathrm{Si}$, which is $300 \mathrm{~nm}$. To make a measurement, a current is

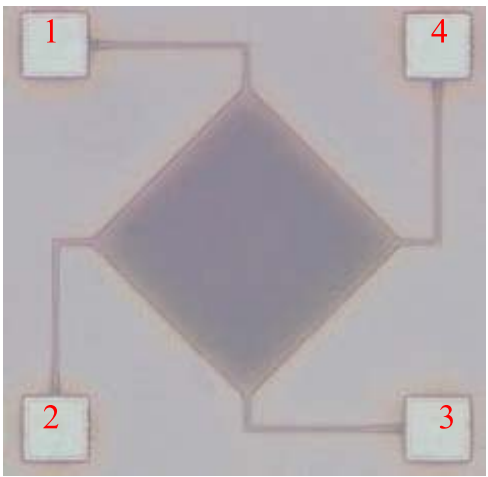

Fig. 1. Van-der-Pauw test structure to measure resistivity and contact resistivity of the poly-Si.

applied to flow along one edge of the sample (for instance, $I_{12}$ ) and the voltage across the opposite edge (in this case, $V_{34}$ ) is measured. From these two values, a resistance (for this example, $R_{12,34}$ ) can be found using Ohm's law:

$$
R_{S}=V_{34} / I_{12}
$$

With the same method, $R_{23,41}$ can also be measured. Then the sheet resistance $R s$ can be defined as followed [46]:

$$
e^{-\pi R_{12,34} / R_{s}}+e^{-\pi R_{23,41} / R_{s}}=1
$$

Additionally, by varying the ambient temperature the temperature coefficients of resistance (TCRs) of the poly-Si are measured by getting different I/V curves.

The Seebeck coefficient and thermal conductance were determined by a cantilever test structure as shown in Fig.2, which performs as a single thermocouple using poly-Si and aluminium (Al) as two thermoelectric materials. The cantilever comprises of three layers: thermal $\mathrm{SiO}_{2}$, doped poly-Si and PECVD $\mathrm{SiO}_{2}$, while the narrow $\mathrm{Al}$ line connects the hot-junction and cold-junction for electric signal readout. The geometries of the n-type and p-type cantilever test structure are the same. The thickness of poly-Si in the test structure is $300 \mathrm{~nm}$, while the width is $90 \mu \mathrm{m}$ and the length is $300 \mu \mathrm{m}$. The width of the $\mathrm{Al}$ line is $1 \mu \mathrm{m}$ and the thickness is $300 \mathrm{~nm}$. As the theoretical thermal conductance of $\mathrm{SiO}_{2}$ is much lower than doped poly-Si and the dimensions of $\mathrm{Al}$ metal line is smaller than the cantilever over almost two orders, it is expected that the cantilever can reflect the thermal conductance of the poly-Si.

A micro-heater is arranged at the end of the hot-junction, as shown in Fig.2, to heat up the hot-junction of the test structure. Since the Seebeck coefficient of poly-Si varies with the temperature of the device and the micro-heater will inevitably affect the temperature of the device, it is crucial to make sure that the temperature rise caused by the micro-heater will be minimized and not affect the performance of the thermopile too much. Our previous work [42] shows that the output voltage at different temperatures is linear with the applied input power. Therefore it can be concluded that the testing results of the test key are still reasonable. The measurement results are shown in Table I.

In order to get the Seebeck coefficient and thermal conductivity of poly-Si, the temperature at the hot-junction need 


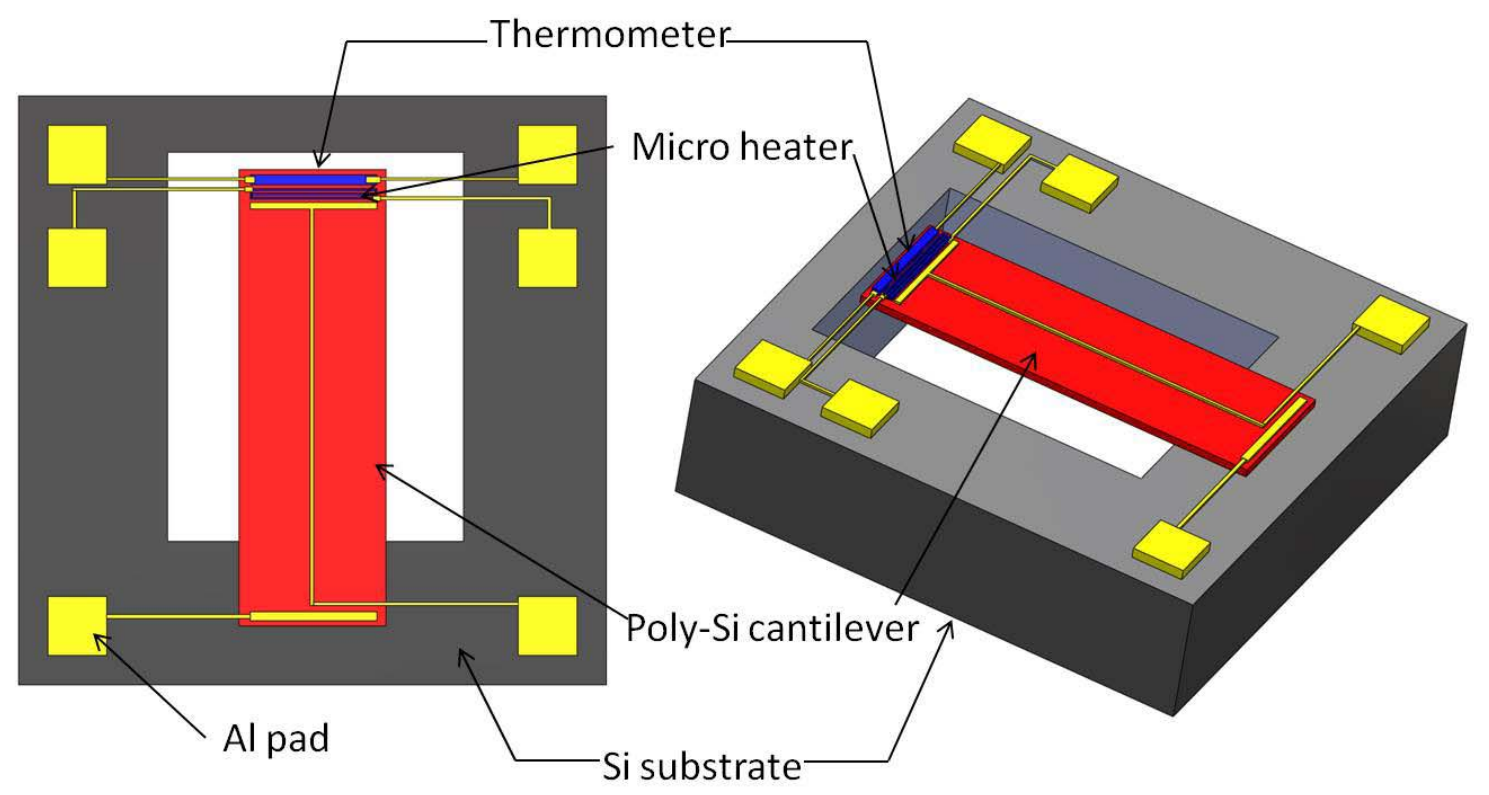

Fig. 2. Schematic drawing of the test structure.

TABLE I

Thermoelectric Properties OF THE HeAVILY Doped Poly-Si AT RoOM TEMPERATURE

\begin{tabular}{lllll}
\hline & $\begin{array}{l}\text { Electric } \\
\text { resistivity } \\
(\mu \Omega m)\end{array}$ & $\begin{array}{l}\text { TCR } \\
(\% / K)\end{array}$ & $\begin{array}{l}\text { Seebeck } \\
\text { coefficient } \\
(\mu \mathrm{V} / \mathrm{K})\end{array}$ & $\begin{array}{l}\text { Thermal } \\
\text { conductivity } \\
(\mathrm{W} / \mathrm{m} K)\end{array}$ \\
\hline p-type & 13.7 & -0.17 & 137 & 33.6 \\
n-type & 8.9 & -0.22 & -118 & 31.9 \\
\hline
\end{tabular}

to be obtained, since the temperature at the cold-junction equals to the temperature of the substrate, which reflects the ambient temperature. As shown in Fig.2, a thermometer made by poly-Si is arranged at the end of the hot-junction to monitor the temperature. For purpose of temperature monitoring, temperature coefficients of resistance (TCRs) of the poly-Si need to be obtained. The Van-der-Pauw test structure, shown in Fig.1, was used to determine TCR of the heavily doped poly-Si, which is about $-0.22 \% / \mathrm{K}$ and $-0.17 \% / \mathrm{K}$ for $\mathrm{n}$-type poly-Si and p-type poly-Si, respectively.

The temperature difference between the cold junction and the hot junction can be derived by using equation 17 .

$$
R(T)=R\left(T_{0}\right) *\left(1+T C R *\left(T-T_{0}\right)\right)
$$

where $R(T)$ is the resistance at temperature $T$ while $R\left(T_{0}\right)$ is the resistance at the original temperature. Fig. 3 shows the average measurement results of the Seebeck coefficient of the n-type poly-Si and the p-type poly-Si from four different test keys with the same design. The diversion of the data got from these four test key are less than 3\%, which proves therepeatability of this experiment.

According to Fig.3(a), the magnitude of the Seebeck coefficient of the p-type heavily doped poly-Si is increasing with temperature but saturates and even decrease over $250{ }^{\circ} \mathrm{C}$. By comparing the Seebeck coefficient of p-type heavily doped
poly-Si at $-50{ }^{\circ} \mathrm{C}$ and $250{ }^{\circ} \mathrm{C}$, a significant increase can be observed. The Seebeck coefficient of the p-type heavily doped poly-Si increases over $400 \%$ at $300{ }^{\circ} \mathrm{C}$ in comparison to $0{ }^{\circ} \mathrm{C}$. Fig.3(b) shows the calculated Seebeck coefficient of the n-type heavily doped poly-Si. Similar to the case of p-type poly-Si, the magnitude of the Seebeck coefficient of n-type heavily doped poly-Si increases largely with temperature while saturates and even decrease over $250{ }^{\circ} \mathrm{C}$. In another aspect, the increasing rate of the magnitude of the Seebeck coefficient of the n-type heavily doped poly-Si is not as significant as for the p-type. The magnitude of the Seebeck coefficient increase only about $150 \%$ for this case.

In order to express the relationship between the Seebeck coefficient of the heavily doped n/p-type poly-Si and the temperature, a cubic polynomial curve fitting is conducted. The solid lines in Fig.3 present the fitted cubic polynomial curve.

Using equation 17 , we can calculate the temperature difference between cold-junction and hot junction. Additionally the thermal conductance can also be calculated with equation 18 :

$$
C_{S_{i}}=P_{\text {in }} * \Delta T=P_{\text {in }} *\left(T-T_{0}\right)
$$

where $C_{S_{i}}$ is the thermal conductance of the polysilicon, $P_{i n}$ is the energy applied in the experiment which can be expressed as:

$$
P_{\text {in }}=V_{\text {in }}^{2} / R_{\text {heater }} \text {. }
$$

The obtained results show that the thermal conductivity of the heavily doped poly-Si is not significantly changed with temperature. The electric resistivity at room temperature, TCR, Seebeck coefficient at room temperature and the thermal conductivity are shown in Table I.

\section{B. Design and Development of the Interferometric Absorber}

In this paper we present a simple absorber structure which can be applied on any infrared sensor. This absorber comprises 


\section{(a)}

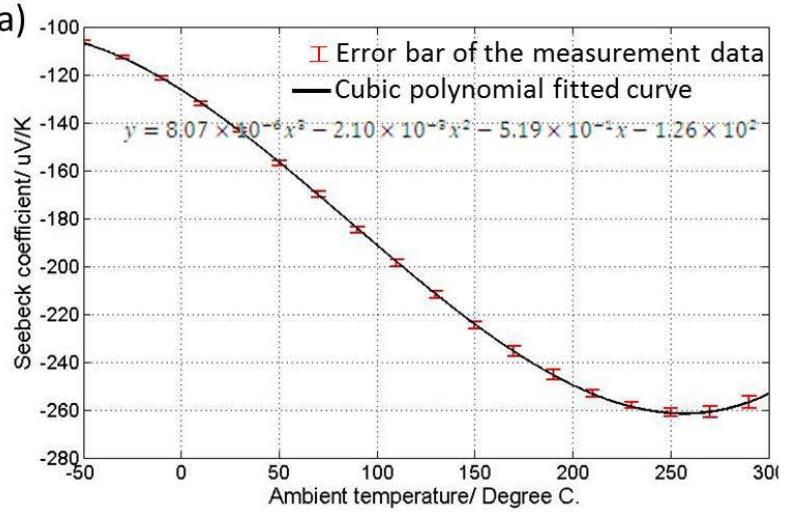

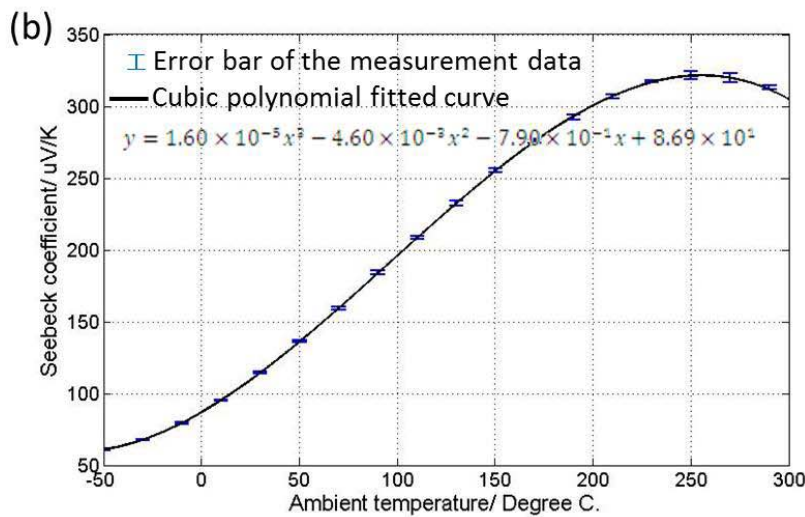

Fig. 3. Seebeck coefficient of p-type (a) and n-type (b) heavily doped polysilicon in different temperature.

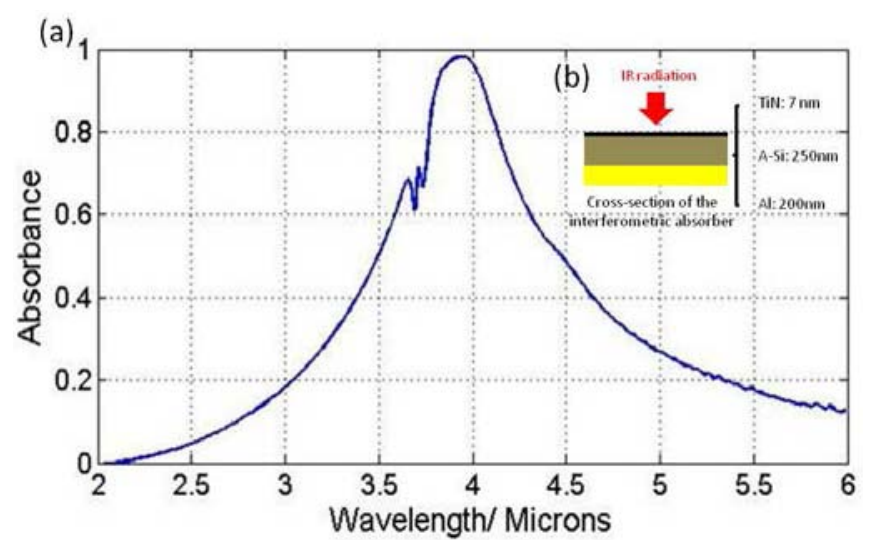

Fig. 4. FTIR measured data of the interferometric absorber (a) and the schematic drawing of the interferometric absorber (b).

an ALD deposited TiN film, an amorphous silicon dielectric layer and a high conductive metal reflector.

A thin film with the sheet resistance of $189 \Omega / \square$ will absorb $50 \%$ of the incident radiation. Due to the impedance matching with the atmospheric impedance, reflection can be minimized. The dielectric layer is chosen to maintain a distance between the reflector and the absorber of $1 / 4$ optical wavelength for the IR-light and therefore contribute to an interferometric enhancement which will ideally provide $100 \%$ of absorption for the required wavelength. K.C. Liddiard conducted a theoretical analysis of the absorption of this 3-layer structure, in which the absorption rate $a$ is a function of the wavelength $\lambda$ [39].

According to K.C. Liddiard's report, the absorption rate depends on the sheet resistance of the top TiN nano thick layer, which should be $377 \Omega / \square$, while the position of the absorption peak depends on the thickness and refractive index of the dielectric layer. In this paper, thickness of the top TiN layer is $7 \mathrm{~nm}$ and the backside reflection $\mathrm{Al}$ layer is $300 \mathrm{~nm}$. The dielectric layer is amorphous Silicon (A-Si) with the refractive index around 4 and the thickness is chosen to be $250 \mathrm{~nm}$.

An FTIR (Fourier Transform Infrared Spectroscopy) is utilized to measure the absorption spectrum and the measurement results are shown in Fig.4(a). Fig.4(a) shows that the absorption peak is around $3.9 \mu \mathrm{m}$ at which the absorption rate can reach about $99 \%$. There is small fluctuation in the spectrum near $3.7 \mu \mathrm{m}$, which cannot be explained by the

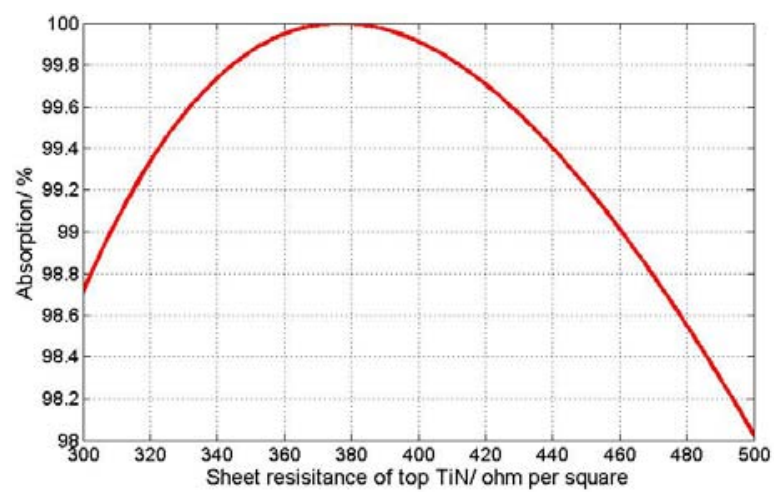

Fig. 5. Simulation of the absorption at $3.9 \mu \mathrm{m}$ with different sheet resistance of top TiN.

theory discussed above. In order to figure out the reason of this fluctuation further investigation will be conducted in future study.

Since this mid-IR sensor is designed for high temperature applications, it is crucial to study the behavior of the absorber at various temperature. According to the previous description the main influence from temperature lies on the resistance change of the top TiN layer along with temperature. The temperature coefficient of resistance (TCR) of TiN is in $10^{-4} \mathrm{~K}^{-1}$ [47]. Thus the derived resistance difference of TiN between $-50{ }^{\circ} \mathrm{C}$ and $300{ }^{\circ} \mathrm{C}$ should be less than $10 \%$. Using equations presented in K.C. Liddiard's work [39], the simulation of the absorption at $3.9 \mu \mathrm{m}$ with different sheet resistance of top TiN was conducted. Figure 5 reveals the simulation results that the absorption at $3.9 \mu \mathrm{m}$ is changed less than $2 \%$, even when the sheet resistance of the top TiN layer is changed from $300 \Omega / \square$ to $500 \Omega / \square$. In this work the design sheet resistance of the top TiN layer is $377 \Omega / \square$. This simulation result indicates that the absorption behavior of the absorber is quite stable at the temperature from $-50{ }^{\circ} \mathrm{C}$ and $300{ }^{\circ} \mathrm{C}$.

\section{Configuration of Thermopile}

In order to optimize the performance of the thermopile IR sensor, we use a thermopile structure of a stacked double layer (SDL), which was reported in our previous work [42]. 


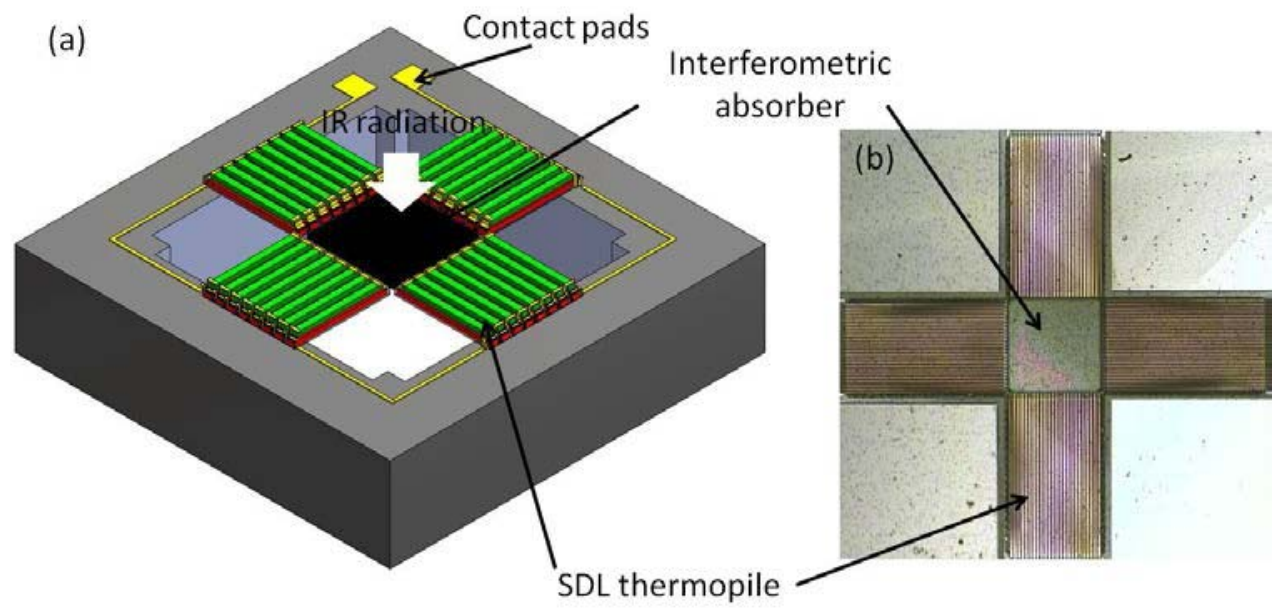

Fig. 6. Schematic drawing of the SDL mid-IR sensor (a) and the optical microscope photo of the IR sensor after released (b).

Fig. 6(a) shows a cross-beam-like thermopile structure which comprises an interferometric absorber. The absorber which absorbs the infrared radiation, is deposited in the central part of the cross leading to temperature rise at the hot junction.

The whole thermopile is suspended on a thin $\mathrm{SiO}_{2}$ membrane. The suspended structure constrains the heat to make sure the heat transfers only through the thermopile, which is connecting the hot-junction and cold-junction. The silicon substrate connected to the end of the cross has high thermal conductance and large thermal mass to maintain a relatively constant temperature at the cold-junction. As a result, when the device is exposed to an IR radiation, there will be a temperature difference between the hot-junction and cold-junction, leading to a voltage drop between these two junctions. Such a voltage drop is read out through the contact pads.

The structure of the interferometric absorber is shown in Fig. 4(b). The absorber is formed with three layers: $7 \mathrm{~nm}$ Titanium Nitride (TiN) on the top, $250 \mathrm{~nm}$ amorphous Silicon (A-Si) in the second layer and $300 \mathrm{~nm}$ Aluminum at the bottom. According the our previous work [42] the optimal dimension parameters are as follows: the length of the thermopile equals to $600 \mu \mathrm{m}$, the width of the thermopile equals to $12 \mu \mathrm{m}$ and the number of thermopile equals to 96 . The thickness of the poly-Si strips are $300 \mathrm{~nm}$ and the thickness of the $\mathrm{SiO}_{2}$ electrical isolation layer is $150 \mathrm{~nm}$.

\section{Temperature Study of Thermopile Mid-IR Sensor}

According to the measurement results of the thermal conductivity, Seebeck coefficient and the electric resistivity, it is possible to predict that the performance of the thermopile increase along the temperature up to at least $250{ }^{\circ} \mathrm{C}$. However, according to the equation 5 , the energy received by the sensor will decrease when the ambient temperature rise under the condition that the source temperature is fixed and equation 3 shows that the output signal will decrease proportional along with the absorbed power received by the sensor.

A theoretical investigation of the energy received by the mid-IR sensor at different ambient temperature was conducted by using the Stefan-Boltzmann law. The simulation results are

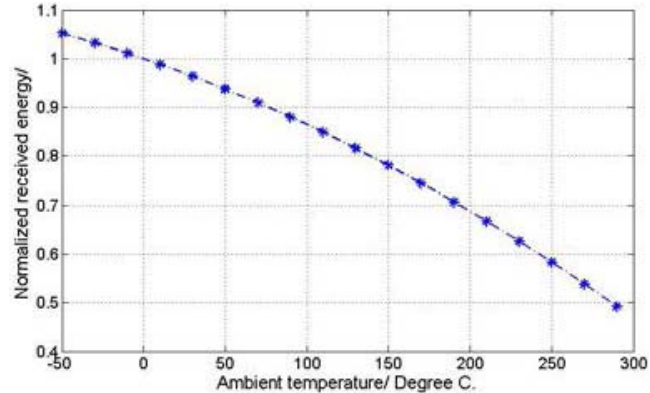

Fig. 7. Normalized energy received by the mid-IR sensor in different temperature.

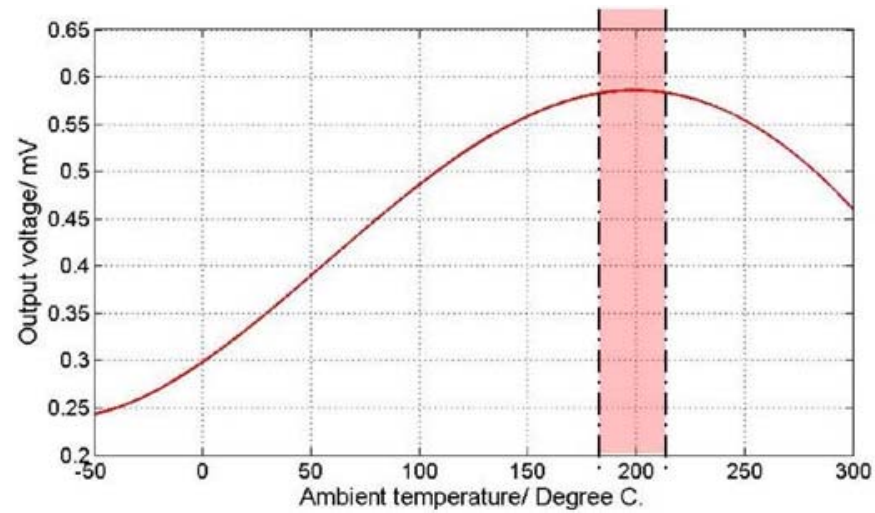

Fig. 8. Simulation results of the thermopile mid-IR sensor at different temperature.

normalized to the energy received by the sensor at $0{ }^{\circ} \mathrm{C}$. The data shown in Fig. 7 indicates that the energy received by the mid-IR sensor decreases significantly with the ambient temperature.

As the discussion above indicates, there is a contradiction between the performance of the thermopile structure and the energy received by the sensor. Therefore, it is reasonable to predict that there could be a balance point to ambient temperature at which the sensor output voltage reaches its highest value. Thus a simulation was conducted to predict this balance point. The material properties applied in the 


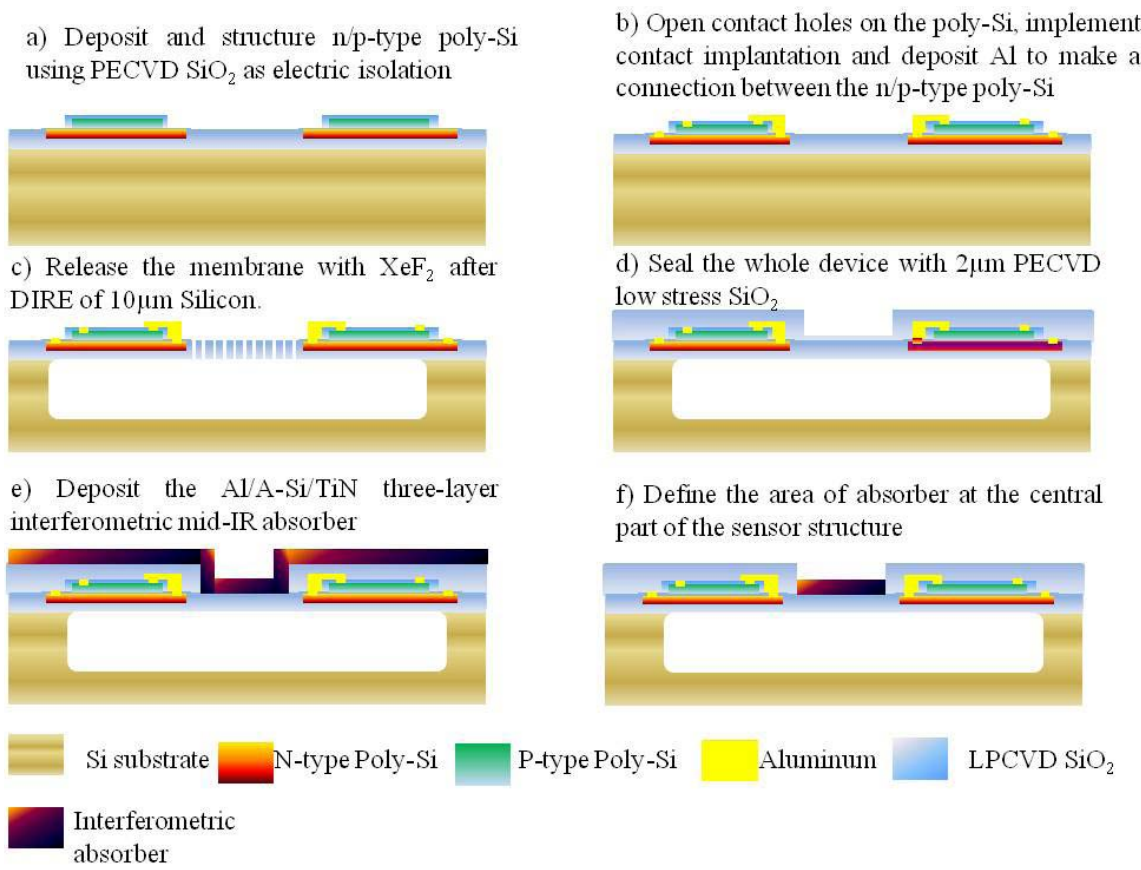

Fig. 9. Micro-fabrication process flow of thermopile. (a) Deposit and structure n/p-type poly-Si using $\mathrm{PECVD} \mathrm{SiO}_{2}$ as electrical isolation. (b) Open contact holes on the poly-Si, implement contact implantation and deposit $\mathrm{Al}$ to make a connection between the n/p-type poly-Si. (c) Release the membrane with $\mathrm{XeF} 2$ after DRIE for 10 min. (d) Seal the whole device with $2 \mu$ m PECVD low stress $\mathrm{SiO}_{2}$. (e) Deposit Al/A-Si/TiN three-layer interferometric mid-IR absorber. (f) Define the area of absorber at the central part of the sensor structure.

simulation are the measurement data presented in section 2.1 while the dimensions of the structure are same as we present in section 2.3. The source temperature is fixed to be $470{ }^{\circ} \mathrm{C}$, the same to the setup of the experiment presented in section VI. As shown in Fig. 8, the output voltage turns to decrease when the ambient temperature is around $200{ }^{\circ} \mathrm{C}$. The IR test to fit the simulation results are shown in section VI.

\section{MICRO-FABRICATION}

Fig. 9 shows the micro-fabrication process flow of the wave length selective thermopile based IR sensor. The starting substrate is an 8 " silicon wafer with $725 \mu \mathrm{m}$ thickness. Firstly, n/p-type poly-Si strips are deposited and structured with thickness of $300 \mathrm{~nm}$. The implantation condition is same as we reported in previous work [42]. PECVD $\mathrm{SiO}_{2}$, with thickness of $150 \mathrm{~nm}$, is deposited as electric insulation layer between the n/p-type poly-Si and on the top of whole wafer [Fig. 9(a)]. Then the contact holes on poly-Si strip are open. After the contact hole open a heavy implantation is conducted to reduce the contact resistance between poly-Si and aluminum (Al). The implantation condition refers to our previous work in [42].

Then $\mathrm{Al}$ layer was deposited by sputtering and patterned to form metal interconnection between n-type and p-type poly-Si strips. To establish good ohmic contact between the $\mathrm{Al}$ and poly-Si, the wafer was annealed at $420{ }^{\circ} \mathrm{C}$ for 30 minutes [Fig. 9(b)]. In order to confine the heat flux within the thermopile beams, the whole device is release with $\mathrm{XeF}_{2}$ to form a cavity after the deep silicon trenches via deep reactive ion etching (DRIE) based on $\mathrm{SF}_{6}$ and $\mathrm{C}_{4} \mathrm{~F}_{8}$ gases for $10 \mu \mathrm{m}$ [Fig. 9(c)]. Following with the release step, $2 \mu \mathrm{m}$ PECVD $\mathrm{SiO}_{2}$ is deposited to seal the release hole so that the mechanic strength is enhanced to support the further fabrication of the interferometric absorber [Fig. 9(d)]. Besides, the pressure used in the PECVD process is about $0.5 \mathrm{mbar}$ which is vacuum. Therefore, the thermal conductance from the air is also minimized by the sealing process.

After the sealing process, the stacked three layer absorption structure is deposited in the central part of the IR sensor with the dimension as the discussion in previous section [Fig. 9(e) and Fig. 9(f)].

\section{EXPERIMENT RESUlt AND Discussion}

\section{A. Electrical Testing}

In order to characterize the thermopile based IR sensor, the features of the thermopile structure need to be characterized first. According to the simulation mentioned in our previous work [41], the impact of using a micro-heater to imitate the IR source with the same power is less than $1 \%$ compare to the real blackbody IR source. Fig.10 shows the electrical measurement which was carried out using a semiconductor parameter analyzer (Agilent technology, 4156C) equipped with a probe station (Cascade Microtech, PMV200).

A bias voltage is applied from $-5 \mathrm{~V}$ to $5 \mathrm{~V}$ in steps of $0.1 \mathrm{~V}$ to get the electrical response of the thermopile structure. The input voltage can be converted into input power by equation 19.

By taking $P_{\text {in }}$ and the measured output voltage $V_{\text {out }}$ into equation 3, the responsivity of the thermopile is calculated. The calculation results are shown in Fig.11. The dotted points are the measured responsivity while the solid line is the simulated data.

The simulation was conducted with the theory and measured materials properties mentioned in section II. The thermal conductivity of poly-Si has been obtained and discussed in 


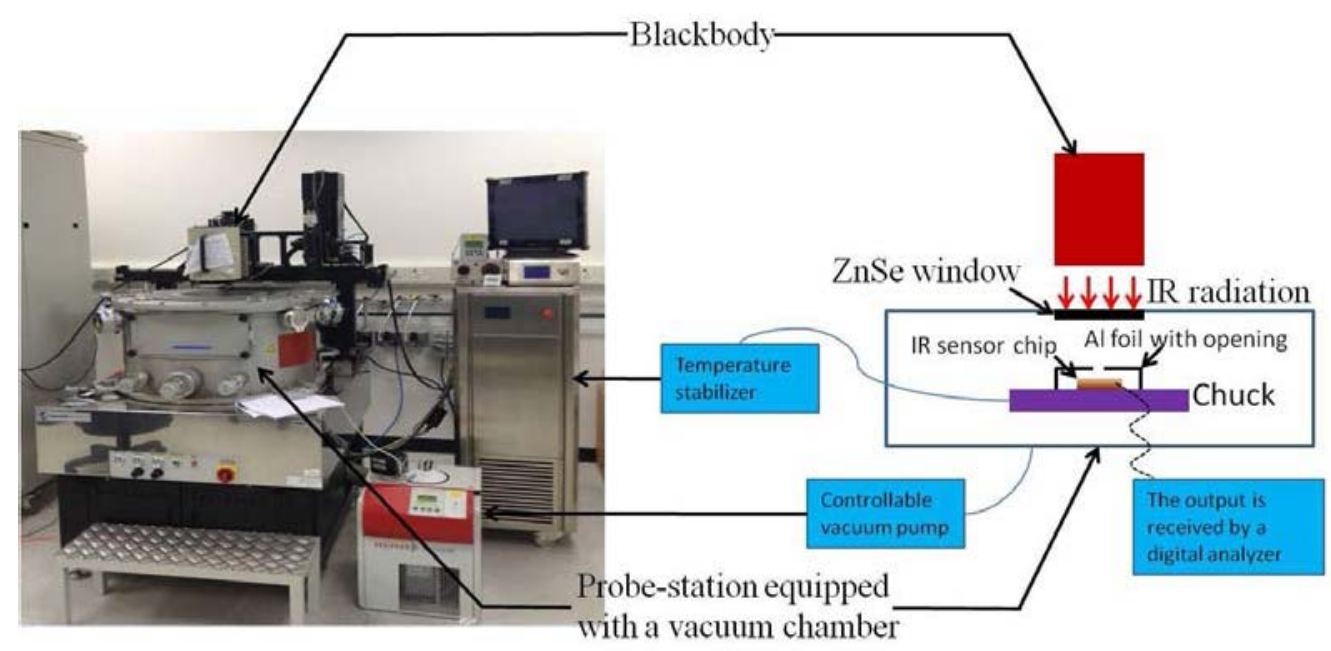

Fig. 10. Experimental setup for the IR measurement and temperature dependent study.

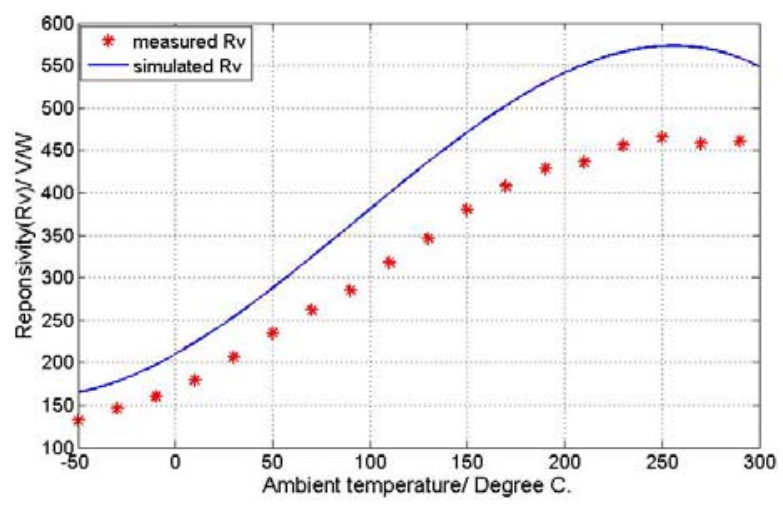

Fig. 11. Electric measurement results of the SDL thermopile.

section II while the Seebeck coefficient used in this simulation is the fitted cubic polynomial curve.

As shown in Fig.11, the responsivity of this thermopile mid-IR sensor varies from $130 \mathrm{~V} / \mathrm{W}$ to $463 \mathrm{~V} / \mathrm{W}$ within the temperature range of $-50{ }^{\circ} \mathrm{C}$ to $300{ }^{\circ} \mathrm{C}$. Besides, responsivity from both of the measurement and the simulation result increase along with the temperature rising and slightly decrease after reaching $250{ }^{\circ} \mathrm{C}$. The highest responsivity, when the ambient temperature is $250{ }^{\circ} \mathrm{C}$, is around $350 \%$ compared to the lowest responsivity at the ambient temperature of $-50{ }^{\circ} \mathrm{C}$. The simulated responsivity and the measured one are in the same trend, but the simulated responsivity is slightly higher than that of the measured one. This difference might be because of that the thermal cross talk between each thermocouple is not considered in the simulation [31], [48].

\section{B. Radiation Testing}

After the electrical measurement, the characterization of the thermopile based IR sensor was conducted. The measurement setup is shown in Fig.10. The blackbody IR source with temperature of $470{ }^{\circ} \mathrm{C}$ is fixed on the top of the vacuum chamber which is equipped with a $\mathrm{ZnSe}$ window. According to the Planck's curve, the radiation peak is around $3.9 \mu \mathrm{m}$, which

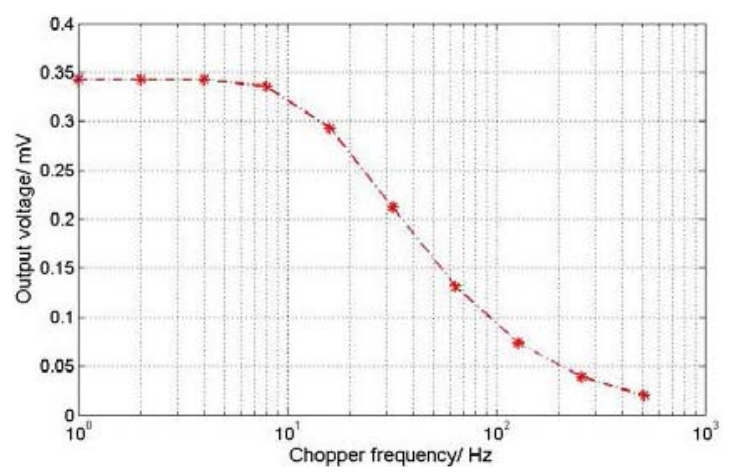

Fig. 12. IR measurement results of the thermopile at room temperature.

matches with the design of the absorber. The IR transmission of the $\mathrm{ZnSe}$ window is around $80 \%$ to ensure that the response of the IR sensor is large enough to be detected. In order to avoid the area other than absorber in detector chip receives too much radiation from blackbody even more than the absorber, an aluminum foil with a $0.4 \mathrm{~mm}$ by $0.4 \mathrm{~mm}$ open hole is placed on the top of the chip as shown in Fig. 10. The blackbody IR source is equipped with a chopper at the frequency from $2 \mathrm{~Hz}$ to $512 \mathrm{~Hz}$ such that the time constant is obtained from the IR measurement results. The IR measurement was conducted for 1000 times to test the working stability of the IR sensor. The time constant was decided by the time required to reach $63 \%$ of the maximum detector output voltage [49]. According to the IR measurement results at room temperature (as shown in Fig.12), the cut-off frequency is around $30 \mathrm{~Hz}$ which means the time constant is around $33 \mathrm{~ms}$, where the time constant is determined by the thermal conductance or resistance and thermal capacitance based on the equation 20.

$$
\tau=R_{\text {ther }} \times C_{\text {ther }},
$$

where $\tau$ is the time constant, $R_{t h e r}$ is the thermal resistance and $C_{\text {ther }}$ is the thermal capacitance. The calculated time constant with equation 20 is $32.4 \mathrm{~ms}$, which is close to the measurement results. 


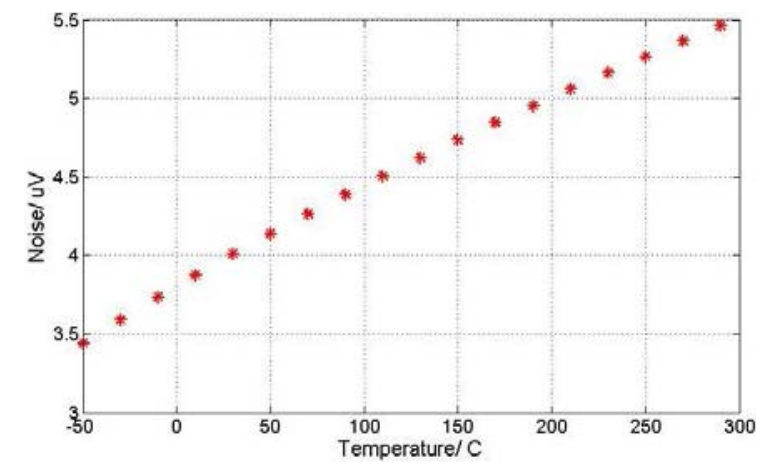

Fig. 13. Measured noise of the thermopile mid-IR sensor at different temperature.

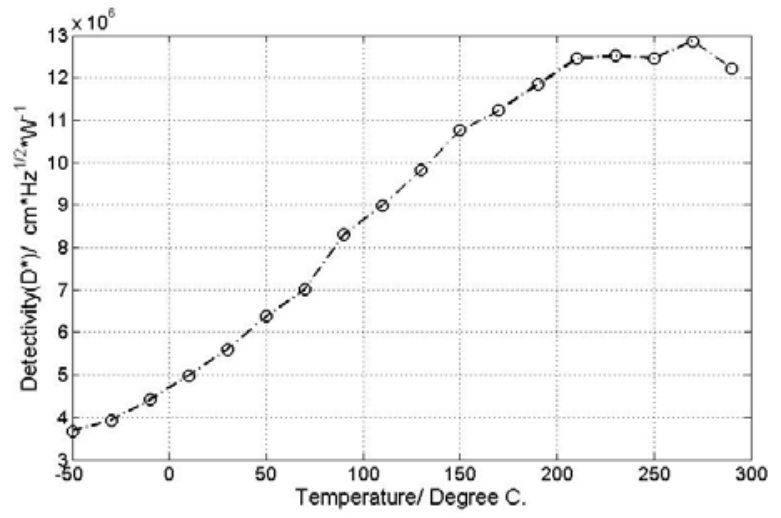

Fig. 14. The derived detectivity of the thermopile.

In order to derive the detectivity of the mid-IR sensor, the measurement of noise at different working temperature was conducted and the results are shown in Fig. 13. According to the theory of thermopile discussed in section II, there is only Johnson noise which can be calculated by equation 11 . The measured overall electric resistance of the thermopile structure is $610 \mathrm{k} \Omega$ and the theoretical noise at room temperature is estimated at $0.2 \mu \mathrm{V} / \Delta f^{1 / 2}$. The electric bandwidth is given as $400 \mathrm{~Hz}$ for Digital Analyzer 5000a (Agilent). In this paper, we do not focus on the optimization of read out circuit design so that the optimized electric bandwidth of the readout circuit is not explored. General speaking, when the optimized electric bandwidth of the readout circuit could be limited to around $1 \mathrm{~Hz}$, the noise will be much smaller and the $\mathrm{D} *$ could be one order higher than the measured value. By using the measured noise shown in Fig. 13 and measured responsivity in Fig.11, the specific detectivity, $\mathrm{D} *$, is calculated as $3.8 * 10^{6} \mathrm{~cm} *$ $\mathrm{Hz}^{1 / 2} * \mathrm{~W}^{-1}$ to $1.3 * 10^{7} \mathrm{~cm} * \mathrm{~Hz}^{1 / 2} * \mathrm{~W}^{-1}$ from $-50{ }^{\circ} \mathrm{C}$ to $300{ }^{\circ} \mathrm{C}$ as shown in Fig. 14 .

According to the discussion in the end of section 2.1, the authors predict that the ambient temperature can be optimized to obtain a highest output signal when the source temperature is fixed. This is because the performance of the thermopile structure increases along with the device temperature significantly but the radiation strength decreases when the device temperature increases. In order to verify this prediction and find an optimized device temperature, an experiment with the

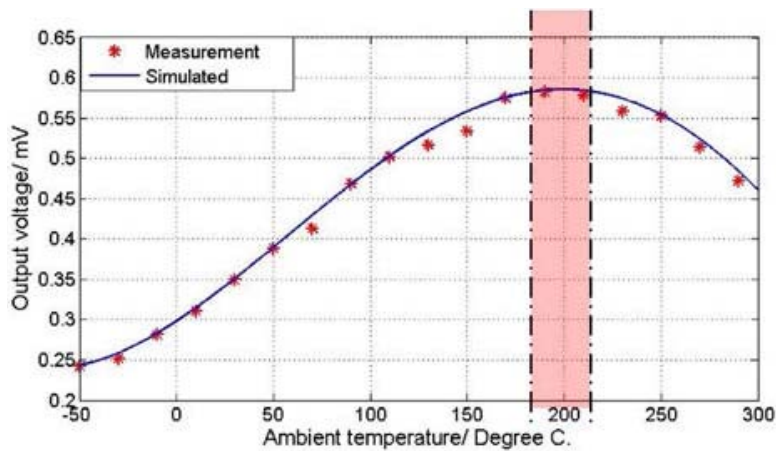

Fig. 15. IR test of the thermopile at different temperature.

blackbody IR source was conducted. The temperature of the blackbody source is $470{ }^{\circ} \mathrm{C}$ as the same to the experiment discussed in previous section.

\section{Infrared Measurement at Different Temperature}

The measurement results are shown in Fig.15. As shown in Fig.15, the output voltage decreases when the ambient temperature is over $190{ }^{\circ} \mathrm{C}$, while the thermopile structure provides the highest $R_{v}$ at $250{ }^{\circ} \mathrm{C}$, as shown in Fig.11. The solid blue line is the simulated results the same as in Fig. 8 and the red stars present the measurement data. This result indicates that the impact of the rising of thermopile structure performance is less than the impact of decreasing of the radiation intensity. As a result, it is proper to claim that the ambient temperature balance point is $190{ }^{\circ} \mathrm{C}$ when the source temperature is $470{ }^{\circ} \mathrm{C}$. The small difference between the measurement results and simulation results shown in section 2 is due to the difference of measurement values and fitted values of the Seebeck coefficient.

\section{CONClusion}

In this paper a CMOS compatible Mid-infrared wavelengthselective thermopile sensor comprising an SDL thermopile and an interferometric absorber is reported. The design, analysis, micro-fabrication and testing of the SDL thermopile structure and the interferometric absorber are presented. The absorption peak of the three-layer interferometric absorber is around $3.9 \mu \mathrm{m}$ at which the absorption rate can reach about $99 \%$. The study of the thermoelectric properties of heavily doped $\mathrm{n} / \mathrm{p}$-type poly-Si indicates that the thermopile structure performs better at high temperature, which matches with the electrical testing results of the thermopile structure. An experiment of IR measurement in different ambient temperature was also conducted to obtain an optimized ambient temperature when the source temperature is $470{ }^{\circ} \mathrm{C}$. The time constant is derived from the measurement results as $33 \mathrm{~ms}$. Considering the output voltage, the fabricated IR sensor gives the maximum value of $0.59 \mathrm{mV}$ at the ambient temperature of $190{ }^{\circ} \mathrm{C}$, where the responsivity and the detectivity are derived as $425.7 \mathrm{~V} / \mathrm{W}$ and $1.25 * 107 \mathrm{~cm} * \mathrm{~Hz}^{1 / 2} * \mathrm{~W}^{-1}$, respectively. The aforementioned results suggest that the developed thermopile based mid-IR sensor are good at applications operated at temperature around $200{ }^{\circ} \mathrm{C}$. 


\section{REFERENCES}

[1] R. A. Wood, C. J. Han, and P. W. Kruse, "Integrateduncooled IR detector imaging arrays," in 5th IEEE Solid State Sens., Actuat. Workshop Tech. Dig., Jun. 1992, pp. 132-135.

[2] A. Schaufelbuhl et al., "Uncooled low-cost thermal imager based on micromachined CMOS integrated sensor array," J. Microelectromech. Syst., vol. 10, no. 4, pp. 503-510, 2001.

[3] S. Eminoglu, M. Y. Tanrikulu, and T. Akin, "A low-cost $128 \times 128$ uncooled infrared detector array in CMOS process," J. Microelectromech. Syst. , vol. 17, no. 1, pp. 20-30, 2008.

[4] C. H. Du and C. Lee, "Characterization of thermopile based on complementary metal-oxide-semiconductor (CMOS) materials and post CMOS micromachining," Jpn. J. Appl. Phys., vol. 41, no. 6B, pp. 4340-4345, 2002.

[5] R. A. Wood, "Uncooled thermal imagingwith monolithic silicon focal arrays," Proc. SPIE, vol. 2020, pp. 322-329, Nov. 1993.

[6] N. Neumann, M. Ebermann, K. Hiller, and S. Kurth, "Tunable infrared detector with integrated micromachined Fabry-Perot filter," Proc. SPIE, vol. 7, p. 646606, Jan. 2007.

[7] F. A. Carey, Organic Chemistry. New York, NY, USA: McGraw-Hill, 2000, ch. 13.

[8] D. Xu, B. Xiong, Y. Wang, and T. Li, "Robust array-composite micromachined thermopile IR detector by CMOS technology," IEEE Electron Device Lett., vol. 32, no. 12, pp. 1761-1763, Dec. 2011.

[9] H. Wu, A. Emadi, P. M. Sarro, G. de Graaf, and R. F. Wolffenbuttel, "A surface micromachined thermopile detector array with an interference-based absorber," J. Micromech. Microeng., vol. 21, no. 7, p. 074009, 2011.

[10] J. Xie, C. Lee, M. F. Wang, and J. M. Tsai, "Microstructures for characterization of seebeck coefficient of doped polysilicon films," Microsyst. Technol., vol. 17, no. 1, pp. 77-83, 2011.

[11] D. Xu, B. Xiong, G. Wu, Y. Ma, and Y. Wang, "Uncooled thermoelectric infrared sensor with advanced micromachining," IEEE Sensors J., vol. 12, no. 6, pp. 2014-2023, Jun. 2010.

[12] V. Leonov, T. Torfs, P. Fiorini, and C. V. Hoof, "Thermoelectric converters of human warmth for self-powered wireless sensor nodes," IEEE Sensors J., vol. 7, no. 5, pp. 650-657, May 2007.

[13] D. Xu, B. Xiong, and Y. Wang, "Self-aligned thermoelectric infrared sensors with post-CMOS micromachining," IEEE Electron Device Lett., vol. 31 , no. 5, pp. 512-514, May 2010.

[14] S. H. Kong and R. F. Wolffenbuttel, "Spectral performance of a micromachined infrared spectrum analyzer in silicon," Instrum, vol. 54, no. 1, pp. 264-267, Feb. 2005

[15] D. Xu, B. Xiong, and Y. Wang, "Micromachined thermopile IR detector module with high performance," IEEE Photon. Technol. Lett., vol. 23, no. 3, pp. 149-151, Feb. 1, 2011.

[16] M.Almasri, Z. Çelik-Butler, D. P. Butler, A. Yaradanakul, and A. Yildiz, "Uncooled multimirror broad-band infrared microbolometers," J. Microelectromech. Syst., vol. 11, no. 5, pp. 528-535, Oct. 2002.

[17] A. Rogalski, "Infrared detectors: Status and trends," Progr. Quantum Electron., vol. 27, nos. 2-3, pp. 59-210, 2003.

[18] P. M. Sarro, "Integrated silicon thermopileinfrared detectors," Ph.D. dissertation, Electron. Instrum. Lab., Delft Tech. Univ., CN Delft, The Netherlands, 1987.

[19] L. Han, Q. A. Huang, X. P. Liao, and S. Su, "A micromachined inline-type wideband microwave power sensor based on GaAs MMIC technology," J. Microelectromech. Syst., vol. 18, no. 3, pp. 705-714, Jun. 2009

[20] M. von Arx, O. Paul, and H. Baltes, "Process-dependent thin-film thermal conductivities for thermal CMOS MEMS," J. Microelectromech. Syst., vol. 9, no. 1, pp. 136-145, Mar. 2000.

[21] L. LaSpina, A.W. van Herwaarden, H. Schellevis, and W. H. A. Wien, "Bulk-micromachined test structure for fast and reliable determination of the lateral thermal conductivity of thin films," J. Microelectromech. Syst., vol. 16, no. 3, pp. 675-683, Jun. 2007.

[22] R. Lenggenhager, "CMOS thermoelectric infrared sensors," Ph.D. dissertation, Phys. Electron. Lab., ETH Zurich, Zürich, Switzerland, 1994.

[23] W. Glatz, E. Schwyter, L. Durrer, and C. Hierold, " $\mathrm{Bi}_{2} \mathrm{Te}_{3}$-based flexible micro thermoelectric generator with optimized design," J. Microelectromech. Syst., vol. 18, no. 3, pp. 763-772, Jun. 2009.

[24] J. Xie, C. Lee, and H. Feng, "Design, fabrication, and characterization of CMOS MEMS-based thermoelectric power generators," J. Microelectromech. Syst., vol. 19, no. 2, pp. 317-324, Apr. 2010.
[25] H. Yousef, K. Hjort, and M. Lindeberg, "Vertical thermopiles embedded in a polyimide-based flexible printed circuit board," J. Microelectromech. Syst., vol. 16, no. 6, pp. 1341-1348, 2007.

[26] C. G. Mattsson, G. Thungstrom, K. Bertilsson, H. E. Nilsson, and H. Martin, "Fabrication and characterization of a design optimized SU-8 thermopile with enhanced sensitivity," Meas. Sci. Technol., vol. 20, no. 11, p. 115202, 2009.

[27] Z. Wang, V. Leonov, P. Fiorini, and C. Van Hoof, "Realization of a wearable miniaturized thermoelectric generator for human body applications," Sens. Actuators A, Phys., vol. 156, no. 1, pp. 95-102, 2009.

[28] Z. Wang, P. Fiorini, V. Leonov, and C. Van Hoof, "Characterization and optimization of polycrystalline $\mathrm{Si}_{70 \%} \mathrm{Ge}_{30 \%}$ for surface micromachined thermopiles in human body applications," J. Micromech. Microeng., vol. 19, no. 9, p. 094011, 2009.

[29] J. Xie, C. Lee, M. F. Wang, Y. Liu, and H. Feng, "Characterization of heavily doped polysilicon films for CMOS-MEMS thermoelectric power generators," J. Micromech. Microeng., vol. 19, no. 12, p. 125029, 2009.

[30] R. F. Wolffenbuttel, "Silicon micromachining for integrated radiant sensors," Sens. Actuators A, Phys., vol. 30, nos. 1-2, pp. 109-115, 1992.

[31] C. H. Du and C. Lee, "Optimization criteria of CMOS compatible thermopile sensors," Proc. SPIE, vol. 3893, pp. 116-126, Oct. 1999.

[32] C. G. Mattsson, K. Bertilsson, G. Thungström, H.-E. Nilsson, and H. Martin, "Thermal simulation and design optimization of a thermopile infrared detector with an SU-8 membrane," J. Micromech. Microeng., vol. 19, no. 5, p. 055016, 2009.

[33] C. G. Mattsson, G. Thungström, H. Rödjegård, K. Bertilsson, H. E. Nilsson, and H. Martin, "Experimental evaluation of a thermopile detector with SU-8 membrane in a carbon dioxide meter setup," IEEE Sensors J., vol. 9, no. 12, pp. 1633-1638, Dec. 2009.

[34] C. G. Mattsson, G. Thungström, K. Bertilsson, H. E. Nilsson, and H. Martin, "Design of a micromachined thermopile infrared sensor with a self-supported $\mathrm{SiO}_{2} / \mathrm{SU}-8$ membrane," IEEE Sensors J., vol. 8, no. 12, pp. 2044-2052, Dec. 2008.

[35] S. I. Yoon and Y. J. Kim, "A flexible tactile sensor based on a thermoelectric device for simultaneous detection of contact heat and contact force," J. Micromech. Microeng., vol. 20, no. 10, p. 105017 , 2010.

[36] Y. H. Choi, M. Kim, D. H. Kang, J. Sim, J. Kim, and Y. J. Kim, "An electrodynamic preconcentrator integrated thermoelectric biosensor chip for continuous monitoring of biochemical process," J. Micromech. Microeng., vol. 22, no. 4, p. 045022, 2012.

[37] C. H. Du and C. Lee, "3D thermoelectric structures derived from a new mixed micromachining process," Jpn. J. Appl. Phys., vol. 39, no. 12B, pp. 7125-7129, 2000.

[38] K. Masuno1, T. Sawada1, S. Kumagai, and M. Sasaki, "Indirect wavelength selective infrared emitter using surface plasmon polariton," in Proc. 16th Int. Solid-State Sens., Actuators, Microsyst. Conf., Jun. 2011, pp. $1586-1589$

[39] K. C. Liddiard, "Application of interferometric enhancement to selfabsorbing thin film thermal IR detectors," Infr. Phys., vol. 34, no. 4, pp. 319-387, 1993.

[40] R. W. Girdler, A. J. Erickson, and R. P. Von Herzen, "Downhole temperature and shipboard thermal conductivity measurements aboard D/V Glomar challenger in the red sea," Deep Sea Drilling Project 23, US Govt. Printing Office, Washington, DC, USA, Tech. Rep. 23 pp. 879-886, 1974.

[41] A. Roncaglia, F. Mancarella, and G. C. Cardinali, "CMOS-compatible fabrication of thermopiles with high sensitivity in the 3-5 $\mu \mathrm{m}$ atmospheric window," Sens. Actuators B, Chem., vol. 125, no. 1 , pp. 214-223, 2007.

[42] H. Zhou, P. Kropelnicki, J. M. Tsai, and C. Lee, "Development of a thermopile infrared sensor using stacked double polycrystalline silicon layers based on the CMOS process," J. Micromech. Microeng., vol. 23, no. 6, p. $065026,2013$.

[43] A. Boukai, K. Xu, and J. R. Heath, "Size-dependent transport and thermoelectric properties of individual polycrystalline bismuth nanowires," Adv. Mater., vol. 18, no. 7, pp. 864-869, 2006.

[44] G. Mahan, B. Sales, and J. Sharp, "Thermoelectric materials: New approaches to an old problem," Phys. Today, vol. 50, no. 3, p. 42, 1997.

[45] G. Chen, M. S. Dresselhaus, G. Dresselhaus, J. P. Fleurial, and T. Caillat, "Recent developments in thermoelectric materials," Int. Mater. Rev., vol. 48, no. 1, pp. 45-66, 2003. 
[46] L. J. van der Pauw, "A method of measuring specific resistivity and Hall effect of discs of arbitrary shape," Phil. Res. Rep., vol. 13, no. 1, pp. $1-9,1958$.

[47] J. F. Creemer et al., "Titanium nitride for MEMS hotplates," in SAFE 2004; Semiconductor Advances for Future Electronics. Utrecht, The Netherland: STW Technology Foundation, 2004, pp. 742-746.

[48] D. Xu, B. Xiong, and Y. Wang, "A CMOS compatible micromachined thermopile ir sensor with high sensitivity," Solid-State Lett., vol. 13, no. 9, pp. J106-J109, 2010

[49] D. Xu, B. Xiong, and Y. Wang, "Modeling of front-etched micromachined thermopile IR detector by CMOS technology," J. Microelectromech. Syst., vol. 19, no. 6, pp. 1331-1340, 2010.

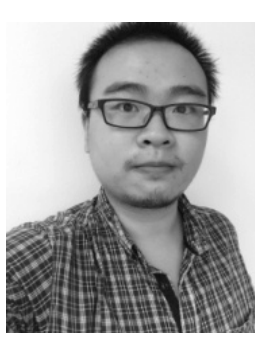

Huchuan Zhou received his B.Eng. degree from the School of Optoelectronic Information at the University of Electronic Science and Technology of China (UESTC), China, in 2010. He is currently pursuing his doctorate degree at NUS under the research scholarship of NUS, Singapore. His research interests include development of novel thermoelectric devices and applications of infrared, focusing mainly on thermopile based infrared sensors and related applications.

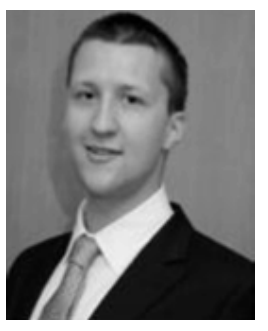

Piotr Kropelnicki was born in Leszno (Poland) on September 20, 1981. He received his Diplom Ingenieur degree in electrical and electronics engineering in 2007 from Universität Duisburg-Essen, Germany with major on microelectronics. He finished his $\mathrm{Ph} . \mathrm{D}$. degree in microelectronics at Fraunhofer Institute for Microelectronic Circuit and Systems, in 2010. He was a principal investigator, leading a team in SAM - Sensors \& Actuators Microsystems Program at the Institute of Microelectronics from 2011 to 2014, being responsible for the development of several MEMS sensors operating in harsh environment, like pressure, IR gas detection, optical, viscosity, and temperature sensors. He is now working with Excelitas Technologies in Singapore, leading R\&D activities in novel sensors.

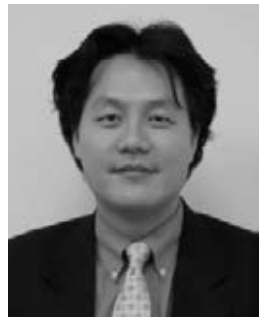

Chengkuo Lee (S'93-M'96) received the M.S. degree in materials science and engineering from National Tsing Hua University, Hsinchu, Taiwan, in 1991; the M.S. degree in industrial and system engineering from Rutgers University, New Brunswick, NJ, in 1993; and the Ph.D. degree in precision engineering from the University of Tokyo, Tokyo, Japan, in 1996. He worked as a Foreign Researcher in the Nanometerscale Manufacturing Science Laboratory of the Research Center for Advanced Science and Technology, University of Tokyo, from 1993 to 1996. He had also worked in the Mechanical Engineering Laboratory, AIST, MITI of Japan as a JST Research Fellow in 1996. Thereafter, he became a Senior Research Staff Member of the Microsystems Laboratory, Industrial Technology Research Institute, Hsinchu, Taiwan. In September 1997, he joined Metrodyne Microsystem Corporation, Hsinchu, Taiwan, and established the MEMS device division and the first micromachining fab for commercial purposes in Taiwan. He was the Manager of the MEMS device division between 1997 and 2000. He was an Adjunct Assistant Professor in the Electrophysics Department of National Chiao Tung University, Hsinchu, Taiwan, in 1998, and an Adjunct Assistant Professor in the Institute of Precision Engineering of National Chung Hsing University, Taichung, Taiwan, from 2001 to 2005. In August 2001, he cofounded Asia Pacific Microsystems, Inc. (APM), where he first became Vice President of R\&D, before becoming Vice President of the optical communication business unit and Special Assistant to the Chief Executive Officer in charge of international business and technical marketing for the MEMS foundry service. From 2006 to 2009, he was a Senior Member of the Technical Staff at the Institute of Microelectronics, A-STAR, Singapore. Currently he is an associate Professor in the Department of Electrical and Computer Engineering, National University of Singapore, Singapore. He is the coauthor of Advanced MEMS Packaging (McGraw-Hill, 2010). He has contributed to more than 200 international conference papers and extended abstracts, and 150 peer-reviewed international journal articles. $\mathrm{He}$ is also the holder of nine U.S. patents. 